\title{
PREVALENCE OF LIFESTYLE AND CARDIOVASCULAR RISK FACTORS IN A GROUP OF MEDICAL STUDENTS
}

\author{
Kvetoslava Rimárová1, Erik Dorko', Jana Diabelková1, Zlatana Sulinová', Peter Urdzík², Nikola Pelechová1, \\ Nika Konrádyová1 \\ ${ }^{1}$ Department of Public Health and Hygiene, Faculty of Medicine, Pavol Jozef Šafárik University in Košice, Košice, Slovak Republic \\ ${ }^{2}$ Department of Gynaecology and Obstetrics, Faculty of Medicine, Pavol Jozef Šafárik University in Košice and Louis Pasteur University \\ Hospital, Košice, Slovak Republic
}

\section{SUMMARY}

Objective: The aim of the cross-sectional study was to evaluate cardiovascular risk factors in the group of medical students with gender, overweight and obesity categorisation.

Methods: Cross-sectional study included 364 medical students, 207 females and 157 males. We investigated anthropometric parameters, BMI, body fat percentage, WHR (waist-hip ratio), TCH (total cholesterol) and LDL-CH (LDL-cholesterol), SBP and DBP (systolic and diastolic blood pressure). The participants also completed questionnaires with socio-demographic characteristic, including smoking, unhealthy eating, self-perceived health, and physical activity status. Statistical analysis used t-test differences in arithmetic means and OR calculation with $95 \% \mathrm{Cl}$.

Results: Prevalence of increased blood pressure (> SBP/DBP $120 / 80 \mathrm{mmHg}$ ) among participants was $10.99 \%$ (SBP) and $9.07 \%$ (DBP). The results confirmed risk of "overweight + obesity" in $15.38 \%$ (using BMl evaluation) versus $18.54 \%$ cases (using body fat percentage evaluation). The results of the study confirmed statistically higher risk for males compared to females in the following parameters: SBP, DBP, BMl, body fat percentage, self-perceived health, unhealthy eating and body weight watching. "Overweight and obesity" group (BMl evaluation) confirmed all factors on statistically significant level a risky group: SBP, DBP, body fat percentage, TCH, self-perceived health, smoking, stress at university, and body weight watching. The outputs confirmed, on the other hand, low amount of clinical obesity ( $0.8 \%$ ), clinical hypertension (BP > 140/90) $1.1 \%$, and clinically higher cholesterol level (TCH>5.2 mmol//) in $8.7 \%$ participants.

Conclusions: We confirmed higher prevalence or cardiovascular risk factors among males. Also, group of "overweight and obese" students had higher frequency of cardiovascular risk factors. Border limits for risk evaluation were strong, so on clinical level we can evaluate the group of medical students as healthy. In the group of young medical students, we confirmed lower frequency of risk factors compared to the Slovak population average.

Key words: cardiovascular risk factors, medical, students, habit

Address for correspondence: P. Urdzík, Department of Gynaecology and Obstetrics, Faculty of Medicine, Pavol Jozef Šafárik University in Košice and Louis Pasteur University Hospital, Trieda SNP 1, 04011 Košice, Slovak Republic. E-mail: peter.urdzik@upjs.sk

https://doi.org/10.21101/cejph.a5477

\section{INTRODUCTION}

Slovak Republic - similar to the vast majority of Eastern European countries - is characterised by very high prevalence of cardiovascular diseases. Risk factors such as smoking, obesity and overweight, stress, unhealthy eating, physical inactivity, and lipid metabolism disorders are strongly associated with the prevalence of cardiovascular diseases (1-3). Existing high prevalence of risk factors of cardiovascular diseases and large number of people with multiple risk factors in eastern European countries (3) is a challenge for intensive preventive measures aiming to reduce risk factors and promote the health of general population. Early prevention of risk factors may have significant influence on development of cardiovascular diseases, as well as other chronic diseases. The measures will include also public education where the major role can be played by health care staff or medical professionals.

Effective and intensive delivery of the measures in the strategies of primary and secondary prevention can significantly improve health outcomes. Preventive strategies are more effective than medical or pharmacological treatment. The results of previous research have indicated the impact of physicians' own health and lifestyle habits on their counselling practices related to health promotion and particularly cardiovascular diseases prevention. Study findings indicate that physicians' personal health habits are consistent and important predictors of their patients' counselling habits (4). Practising healthy life style can be a crucial factor for counselling activities among future medical doctors or health care staff (4-6).

The majority of research studies on the health status and lifestyle factors of medical students includes cross-sectional studies which contain self-reported data and questionnaires, rather than biochemical, functional or clinical measures of cardio-metabolic risk such as blood pressure and lipid profile (7-9). Longitudinal studies of health status of medical students have shown changes of health determinants during medical studies with repeated measurement of participants $(9,10)$. 
The aim of this paper was to evaluate, in a cross-sectional survey, whether gender determines the prevalence of cardiovascular risk factors. Another aim was to evaluate prevalence of cardiovascular risk parameters in obese and overweight medical students. Participants were general medicine students in their $4^{\text {th }}$ year of studies at medical school. The results will be useful in implementing changes in future curricula and creation of new teaching subjects or seminars with target to improve and sustain good health and lifestyle habits of students during medical school studies.

\section{MATERIALS AND METHODS}

Repeated cross-sectional studies (2010-2014) included sample of $4^{\text {th }}$ year general medicine students. Total number of study participants was 364; group consisted of 207 females and 157 males from Medical Faculty, University of Pavol Jozef Šafárik in Košice. Mean age of the participants was 23.47 years for the whole group (men 23.74 years; women 23.24 years). The study investigated the prevalence of cardiovascular risk factors, unhealthy habits and their association with gender, overweight and obesity. Students completed anonymous self-reported questionnaires. Personal questionnaires were based on the methodology of the CINDI programme and included brief information about personal and family history, social data, smoking, physical activity, and dietary habits (11). Self-perceived health was evaluated on 5 scale level (excellent, very good, satisfactory, poor). In the self-administered questionnaires students were assessing how they perceive their own health status using 5 grade scale: excellent; very good; good; satisfactory and poor. Scale evaluation was dichotomized in the analysis - students with answers "excellent and very good" were compared with those who answered "good, satisfactory and poor".

Anthropometric measurements and calculations included body weight, body height, BMI (Body Mass Index) and WHR (Waist Hip Ratio). BMI was derived from body weight expressed in kilograms divided by squared body height $\left(\mathrm{kg} / \mathrm{m}^{2}\right)$. Recognized criteria were used for the assessment of overweight and obesity versus normal BMI (12). Cut-off value for overweight and obesity for females was $\mathrm{BMI} \geq 24$; and for male students it was $\mathrm{BMI} \geq 25$. Flexible and inextensible tape measure with resolution of $0.1 \mathrm{~cm}$ was used to measure waist and hip circumferences immediately above the iliac crests and waist. WHR was calculated as a ratio between the waist circumference and hip circumference.

Body fat percentage evaluation, measuring the thickness of substantial fat stores, was assessed by measuring of selected 4 skinfolds with the use of calliper device HARPENDEN with calibration dowel. The measurement was performed on 4 body sites: scapula, spina iliaca anterior superior, biceps muscle and triceps muscle. Percentage of fat was calculated from the sum of all 4 skinfolds and derived from standards by Parizkova $(13,14)$. Normative standards used for assessment of overweight and obesity, based on body fat percentage, were $>20 \%$ for males and $>25 \%$ for females.

The systolic and the diastolic blood pressure (SBP and DBP) were measured by the traditional sphygmomanometer with participant in a sitting position. The values of systolic and diastolic blood pressures were recorded as the arithmetic mean of three repeated measurements. In a preparation for measurements the participants were seated and rested quietly for at least $15 \mathrm{~min}$ utes prior taking of the first BP measurement. The right arm was used for all blood pressure measurements. All participants had BP measurement taken always by the same researcher and with the same-sized cuff for adults. Time intervals between the measurements were 5-10 minutes. The first (for systolic) and fifth (for diastolic) Korotkoff sounds were recorded for each of the 3 measurements. Our sample consisted of young people only. Instead of the WHO recommended cut-off for BP $-140 / 90 \mathrm{mmHg}$, which is appropriate across the general population, our chosen cut-off point for increased blood pressure was $120 / 80 \mathrm{mmHg}$ for SBP and DBP respectively.

Plasma levels of total cholesterol (TCH) and LDL-cholesterol (LDL-CH) were determined using the REFLOTRON - the biochemistry analyser. Capillary blood was taken with lancets in the morning, in fasting mode of the participants. The blood analysis was processed with cooperation of Regional Public Health Authority in Košice. European guideline for total cholesterol target level in high risk patients was used in the study, with recommended borderline levels: TCH $<4.5 \mathrm{mmol} / 1$ and for LDL-cholesterol $<2.5 \mathrm{mmol} / \mathrm{l}(15,16)$.

The data were analyzed using the Statistical Package for the Social Sciences IBM-SPSS, version 17.0. For the descriptive analysis, absolute and relative frequencies were calculated, as well as central tendency and dispersion measures. The KolmogorovSmirnov test was applied to assess the normality of the sample. OR (Odds Ratio) with $95 \%$ of CI (Confidence Interval) and Chi-square test were used to compare gender and overweight probability of dichotomized cardiovascular risk factor. The rejection level established for the null hypothesis was lower than or equal to $0.05(5 \%)$. The statistical significance of the difference between the sexes of arithmetic means of quantitative variables was calculated using two sample Student's t-test.

Research survey implemented principles of Helsinki declaration in medical research involving human subjects capable of giving informed consent. Each potential subject was adequately informed of the aims, methods, sources of funding, any possible conflicts of interest, institutional affiliations of the researcher, the anticipated benefits and potential risks of the study and the discomfort it may entail. The participants have been informed on the right to refuse to participate in the study or to withdraw consent to participate at any time without reprisal. After ensuring that the subjects of our study have understood the information, the physician or researcher asked for the written informed consent.

\section{RESULTS}

Evaluation of the general prevalence of examined risk factors (Table 1) confirmed BP higher than $120 / 80 \mathrm{mmHg}$ in $10.99 \%$ (SBP) versus $9.07 \%$ (DBP) of medical students. By the BMI standards, we detected $15.38 \%$ overweight and obese students, versus $18.58 \%$ when standards for body fat percentage have been used. Higher prevalence of elevated TCH has been identified in $28.08 \%$ of students, compared to elevated LDL-CH with $16.57 \%$ of participants. Smoking frequency in the group was very low $11.81 \%$. Majority of students $(73.35 \%)$ confirmed self-perceived health as excellent and very good. Stress at university was no- 
Table 1. Basic frequency of exanimated risk factors in medical students group $(N=364)$

\begin{tabular}{|l|c|c|}
\hline \multirow{2}{*}{ Parameter } & \multicolumn{2}{|c|}{ Total } \\
\cline { 2 - 3 } & $\mathbf{n}$ & $\%$ \\
\hline $\mathrm{SBP}>120 \mathrm{mmHg}$ & 40 & 10.99 \\
\hline DBP $>80 \mathrm{mmHg}$ & 33 & 9.07 \\
\hline $\begin{array}{l}\text { BMl males } \geq 25 \\
\text { BMl females } \geq 24\end{array}$ & 56 & 15.38 \\
\hline $\begin{array}{l}\text { Total cholesterol (TCH) } \\
>4.5 \text { mmol/l }\end{array}$ & 100 & 28.08 \\
\hline $\begin{array}{l}\text { LDL-cholesterol (LDL-CH) } \\
>2.5 \text { mmol/l }\end{array}$ & 59 & 16.57 \\
\hline $\begin{array}{l}\text { Body fat percentage } \\
\text { Males } \geq 20 \% \\
\text { Females } \geq 25 \%\end{array}$ & 66 & 18.54 \\
\hline $\begin{array}{l}\text { Perceived health } \\
\text { excellent and very good }\end{array}$ & 267 & 73.35 \\
\hline Smoking & 43 & 11.81 \\
\hline Stress at university & 173 & 47.53 \\
\hline Unhealthy eating & 127 & 34.89 \\
\hline Body weight watching & 217 & 59.62 \\
\hline Low physical activity & 174 & 47.80 \\
\hline
\end{tabular}

$\mathrm{n}$ - number of subjects; SBP - systolic blood pressure; DBP - diastolic blood pressure; BMI - Body Mass Index ticeable in $47.53 \%$ of students, unhealthy eating in $34.89 \%$ of participants. Almost half of the students (47.53\%) reported low physical activity. Body weight watchers were present in $59.62 \%$.

Only $1.1 \%$ of participants ( 3 males and 1 female) were classified by International criteria (17) (SBP vs. DBP > 140/90 mmHg) as being hypertensive. As a standard for BP classification for gender difference, we chose limits SBP vs. DBP $>120 / 80 \mathrm{mmHg}$. Males in our study had statistically significantly higher SBP $(15.9 \%)$, while females only in $7.2 \%(\mathrm{OR}=2.42 ; 95 \% \mathrm{CI}$ $1.23-4.77 ; \mathrm{p}<0.05)$. Similarly to SBP, DBP was also confirmed to be significantly higher in males than females $(\mathrm{OR}=2.18$; $95 \%$ CI $1.05-4.53$; $\mathrm{p}<0.05)$, DBP was increased in $12.7 \%$ of males, versus $6.3 \%$ of females (Table 2 ).

Obesity evaluation confirms very low prevalence of obesity among medical students. Obesity in the range of BMI $\geq 30$ was confirmed only in 2 males and 1 female $(0.8 \%)$. The group of males showed more prevalent frequency of overweight and obesity compared to females. Intersexual comparison between the group with normal BMI ( $\leq 24.99$ for males and $\leq 23.99$ for females) and the group with overweight and obesity was statistically significant: $\mathrm{OR}=2.53 ; 95 \%$ CI $1.40-4.55 ; \mathrm{p}<0.05$. Male students had higher BMI in $22.3 \%$ cases, compared to $10.1 \%$ prevalence in female students (Table 2). The estimation of body fat percentage, which is another evaluation of adiposity, has confirmed slightly higher number of overweight and obese participants than when the BMI assessment was used. Results of body fat percentage evaluation confirmed $24.8 \%$ of males and $13.0 \%$ females exceeded standards for overweight + obesity (Table 2 ); with OR for boys 2.20 (95\% CI 1.28-3.79; $\mathrm{p}<0.01)$.

Table 2. OR of cardiovascular risk factors for males in medical students group $(N=364)$

\begin{tabular}{|c|c|c|c|c|}
\hline Parameter & $\begin{array}{l}\text { Males } \\
\mathrm{n}(\%)\end{array}$ & $\begin{array}{c}\text { Females } \\
\mathrm{n}(\%)\end{array}$ & OR $(95 \% \mathrm{Cl})$ & $p$-value \\
\hline $\mathrm{SBP}>120 \mathrm{mmHg}$ & $25(15.9)$ & $15(7.2)$ & $2.42(1.23-4.77)$ & $<0.05^{*}$ \\
\hline $\mathrm{DBP}>80 \mathrm{mmHg}$ & $20(12.7)$ & $13(6.3)$ & $2.18(1.05-4.53)$ & $<0.05^{*}$ \\
\hline $\begin{array}{l}\text { BMI males } \geq 25 \\
\text { BMl females } \geq 24\end{array}$ & $35(22.3)$ & $21(10.1)$ & $2.53(1.40-4.55)$ & $<0.05^{*}$ \\
\hline $\begin{array}{l}\text { Total cholesterol (TCH) } \\
>4.5 \mathrm{mmol} / \mathrm{l}\end{array}$ & $39(25.4)$ & $61(30.0)$ & $0.80(0.50-1.28)$ & n.s. \\
\hline $\begin{array}{l}\text { LDL-cholesterol (LDL-CH) } \\
>2.5 \mathrm{mmol} / \mathrm{l}\end{array}$ & $22(14.4)$ & $37(18.2)$ & $0.75(0.42-1.34)$ & n.s. \\
\hline $\begin{array}{l}\text { Body fat percentage } \\
\text { Males } \geq 20 \% \\
\text { Females } \geq 25 \%\end{array}$ & $39(24.8)$ & $27(13.0)$ & $2.20(1.28-3.79)$ & $<0.01^{* *}$ \\
\hline $\begin{array}{l}\text { Perceived health } \\
\text { excellent and very good }\end{array}$ & $105(66.9)$ & $162(78.2)$ & $0.56(0.35-0.89)$ & $<0.05^{*}$ \\
\hline Smoking & $22(14.0)$ & $21(10.1)$ & $1.44(0.76-2.73)$ & n.s. \\
\hline Stress at university & $77(49.0)$ & $96(46.5)$ & $1.11(0.73-1.69)$ & n.s. \\
\hline Unhealthy eating & $75(47.8)$ & $52(25.1)$ & $2.73(1.75-4.25)$ & $<0.001^{* * *}$ \\
\hline Body weight watching & $71(45.2)$ & $146(70.5)$ & $0.35(0.22-0.53)$ & $<0.001^{* * *}$ \\
\hline Low physical activity & $69(43.9)$ & $105(50.7)$ & $0.76(0.50-1.15)$ & n.s. \\
\hline
\end{tabular}

$\mathrm{n}$ - number of subjects; SBP - systolic blood pressure; DBP - diastolic blood pressure; BMI - Body Mass Index; $\mathrm{Cl}$ - confidence interval;

p-values ${ }^{* *}<0.001 ;{ }^{* *}<0.01 ;{ }^{*}<0.05 ;$ n.s. - not significant 
International criteria for elevated $\mathrm{TCH}>5.2 \mathrm{mmol} / \mathrm{l}$ were observed in 32 students (8.7\%). Increased TCH levels $>4.5 \mathrm{mmol} / \mathrm{l}$ were confirmed in $25.4 \%$ of males and $30.0 \%$ of females, there was no statistically significant difference between the two gender groups. Insignificant differences were obtained also when comparing gender difference in LDL-cholesterol $>2.5 \mathrm{mmol} / \mathrm{l}$. Elevated LDL-cholesterol levels were declared in $14.4 \%$ of men and $18.1 \%$ in women students (Table 2).

In the self-administered questionnaire (Table 2) female students perceived their health status to be better than the male students, this difference was statistically significant (for boys $\mathrm{OR}=0.56$;

Table 3. Intersexual differences in systolic and diastolic BP in medical students group $(N=364)$

\begin{tabular}{|c|c|c|c|c|c|}
\hline & $\mathrm{n}$ & $\overline{\mathbf{x}}$ & SD & $t$ & $p$-value \\
\hline \multicolumn{6}{|c|}{$\mathrm{SBP}(\mathrm{mmHg})$} \\
\hline Males & 157 & 120.13 & 9.85 & \multirow{2}{*}{9.99} & \multirow{2}{*}{$<0.001^{* * *}$} \\
\hline Females & 207 & 109.10 & 10.85 & & \\
\hline \multicolumn{6}{|c|}{$\mathrm{DBP}(\mathrm{mgHg})$} \\
\hline Males & 157 & 78.08 & 8.99 & \multirow{2}{*}{4.05} & \multirow{2}{*}{$<0.001^{* * *}$} \\
\hline Females & 207 & 74.30 & 8.68 & & \\
\hline
\end{tabular}

$\mathrm{n}$ - number of subjects; SBP - systolic blood pressure; DBP - diastolic blood pressure; $\overline{\mathrm{x}}$ - arithmetic mean; $\mathrm{SD}$ - standard deviation; $\mathrm{t}$ - $\mathrm{t}$-test value; p-value $-{ }^{* * *}<0.001$

Table 4. Intersexual differences in BMI, body fat percentage, total blood cholesterol, LDL-cholesterol in medical students group $(N=364)$

\begin{tabular}{|c|c|c|c|c|c|}
\hline & $\mathrm{n}$ & $\overline{\mathbf{x}}$ & SD & $\mathrm{t}$ & p-value \\
\hline \multicolumn{6}{|c|}{ Body Mass Index } \\
\hline Males & 157 & 23.89 & 5.18 & \multirow{2}{*}{2.49} & \multirow{2}{*}{$<0.5^{*}$} \\
\hline Females & 207 & 22.41 & 5.94 & & \\
\hline \multicolumn{6}{|c|}{ Body fat percentage (4 skinfolds) } \\
\hline Males & 157 & 18.16 & 11.75 & \multirow{2}{*}{4.84} & \multirow{2}{*}{$<0.001^{* * *}$} \\
\hline Females & 207 & 23.75 & 10.22 & & \\
\hline \multicolumn{6}{|c|}{ Total cholesterol (mmol/l) } \\
\hline Males & 153 & 4.31 & 0.98 & \multirow{2}{*}{2.16} & \multirow{2}{*}{$<0.05^{*}$} \\
\hline Females & 203 & 4.52 & 0.85 & & \\
\hline \multicolumn{6}{|c|}{ LDL-cholesterol (mmol/l) } \\
\hline Males & 153 & 2.67 & 0.72 & \multirow{2}{*}{2.17} & \multirow{2}{*}{$<0.05^{\star}$} \\
\hline Females & 203 & 2.85 & 0.81 & & \\
\hline \multicolumn{6}{|c|}{ Waist-Hip Ratio } \\
\hline Males & 157 & 0.88 & 0.057 & \multirow{2}{*}{34.00} & \multirow{2}{*}{$<0.001^{* * *}$} \\
\hline Females & 207 & 0.70 & 0.044 & & \\
\hline
\end{tabular}

$\mathrm{n}$ - number of subjects; $\overline{\mathrm{x}}$ - arithmetic mean; SD - standard deviation; $\mathrm{t}$ - t-test value; $\mathrm{p}$-values $-{ }^{* * *}<0.001 ;{ }^{*}<0.05$
95\% CI 0.35-0.89; $\mathrm{p}<0.05)$. Gender-wise compared, the prevalence of smoking was almost identical, but lower than the average of the overall Slovak population (18). Smoking men prevalence was $14.0 \%$ and smoking females $10.1 \%$. No gender statistical significance was established in the smoking status. In the questionnaires, perceived stress at university was declared in less than half of male $(49.0 \%)$ and female participants (46.5\%), with no statistical gender difference. Unhealthy eating was more frequent in males $(47.8 \%)$ than in females $(25.1 \%)$. Eating habits difference was statistically significant $(p<0.001)$. As it would have been expected from the gender point of view, higher proportion of body-weight-watchers was established among females (70.5\%) compared to males $(45.2 \%)$, with significant outputs $(\mathrm{OR}=0.35$; $95 \%$ CI $0.22-0.53 ; p<0.001)$. No significant differences have been established in the prevalence of low physical activity. Low physical activity was reported in $43.9 \%$ of males and $50.7 \%$ of females, so males appear to be slightly more active in the field of physical activity (Table 2).

Differences in the arithmetic means for SBP and DBP (Table 3 ) were significantly higher among the group of medical males students $(\mathrm{p}<0.001)$. Total cholesterol $(\mathrm{TCH})$ mean level (Table 4) was significantly higher among females $4.52 \mathrm{mmol} / \mathrm{l}$ versus $4.31 \mathrm{mmol} / 1$ among males $(\mathrm{p}<0.05)$. LDL-cholesterol analysis of the samples did not show any significant differences between males $(2.67 \mathrm{mmol} / \mathrm{l})$ and females $(2.85 \mathrm{mmol} / \mathrm{l})$. The body fat percentage (Table 4) was significantly higher among females $(\mathrm{p}<0.001)$, as it would have been expected, based on physiologic gender difference in somatic and body development. The same physiologic anthropometric differences were confirmed in WHR $(\mathrm{p}<0.001)$, with the males having significantly higher WHR (0.88) than females (0.70).

OR calculated for BMI - obese and overweight students (BMI $\geq 24$ for females; BMI $\geq 25$ for males) - defined this group as highly risky (Table 5). Obese and overweight students had higher prevalence of increased SBP (OR $=8.00$; $95 \%$ CI 3.93-16.27; $\mathrm{p}<0.001)$ and DBP $(\mathrm{OR}=12.61 ; 95 \% \mathrm{CI}$ $5.78-27.48 ; \mathrm{p}<0.001)$. Group that exceeded the standards of BMI showed increased risk for higher levels of TCH $(p<0.001)$ and LDL-cholesterol $(p<0.001)$. Perceived general health was also significantly worse in the group of obese and overweight students $(\mathrm{OR}=8.05 ; 95 \%$ CI 4.33-14.98; $\mathrm{p}<0.001)$ when compared to participants with normal BMI. Of course, obese students have statistically higher OR for low prevalence of body weight control (OR $=0.21 ; 95 \%$ CI $0.1-0.40 ; p<0.001)$, showed significantly higher prevalence of smoking and stress at university. We didn't confirm in the "obese + overweight" group unhealthy eating and low physical activity as significant risk factors comparing to the group with normal BMI.

Almost identical statistical differences have bene confirmed when outputs of another system of adiposity evaluation were analysed (Table 6). Students in the range of overweight and obesity evaluated by body fat percentage, showed significantly higher prevalence of risk of cardiovascular and lifestyle factors with the same statistical significance as when the BMI standards have been applied: SBP and DBP $(\mathrm{p}<0.001)$; TCH and LDL-CH $(p<0.001)$; perceived general health $(p<0.001)$ and body weight watching $(\mathrm{p}<0.001)$, higher prevalence of smoking, low physical activity. Unhealthy eating and stress at university haven't been confirmed as statistically significant. 
Table 5. OR of cardiovascular risk factors for group of BMI overweight and obese medical students $(N=364)$

\begin{tabular}{|c|c|c|c|c|c|c|}
\hline Parameter & Category & $n(\%)$ & $\begin{array}{c}\text { BMI higher } \\
\text { n (\%) }\end{array}$ & $\begin{array}{l}\text { BMI normal } \\
n(\%)\end{array}$ & OR $(95 \% \mathrm{Cl})$ & $\mathrm{p}$-value \\
\hline \multirow{2}{*}{ SBP } & Normal & $324(11.0)$ & $36(64.3)$ & $288(93.5)$ & \multirow{2}{*}{$8.00(3.93-16.27)$} & \multirow{2}{*}{$<0.001^{* * *}$} \\
\hline & Higher & $40(89.0)$ & $20(35.7)$ & $20(6.5)$ & & \\
\hline \multirow{2}{*}{ DBP } & Normal & $331(90.9)$ & $36(64.3)$ & $295(95.8)$ & \multirow{2}{*}{$12.61(5.78-27.48)$} & \multirow{2}{*}{$<0.001^{* * *}$} \\
\hline & Higher & $33(9.1)$ & $20(35.7)$ & $13(4.2)$ & & \\
\hline \multirow{2}{*}{$\mathrm{TCH}$} & Normal & $256(71.9)$ & $14(25.0)$ & $242(80.7)$ & \multirow{2}{*}{$12.51(6.41-24.44)$} & \multirow{2}{*}{$<0.001^{\star \star \star}$} \\
\hline & Higher & $100(28.1)$ & $42(75.0)$ & $58(19.3)$ & & \\
\hline \multirow{2}{*}{ LDL-CH } & Normal & $297(83.4)$ & $15(26.7)$ & $282(94.0)$ & \multirow{2}{*}{$42.82(20.04-91.52)$} & \multirow{2}{*}{$<0.001^{* * *}$} \\
\hline & Higher & $59(16.6)$ & 41 (73.2) & $18(6.0)$ & & \\
\hline \multirow{2}{*}{$\begin{array}{l}\text { Perceived } \\
\text { health }\end{array}$} & $\begin{array}{l}\text { Excellent and very } \\
\text { good }\end{array}$ & $267(73.4)$ & $19(33.9)$ & $248(80.5)$ & \multirow{2}{*}{$8.05(4.33-14.98)$} & \multirow{2}{*}{$<0.001^{* * *}$} \\
\hline & $\begin{array}{l}\text { Good, satisfactory } \\
\text { and poor }\end{array}$ & $97(26.6)$ & $37(66.1)$ & $60(19.5)$ & & \\
\hline \multirow{2}{*}{ Smoking } & Yes & $43(11.8)$ & $15(26.8)$ & $28(9.1)$ & \multirow{2}{*}{$3.66(1.80-7.42)$} & \multirow{2}{*}{$<0.001^{* * \star}$} \\
\hline & No & $321(88.2)$ & $41(73.2)$ & $280(90.9)$ & & \\
\hline \multirow{2}{*}{ Stress at university } & Yes & $173(47.5)$ & $35(62.5)$ & $138(44.8)$ & \multirow{2}{*}{$2.05(1.14-3.69)$} & \multirow{2}{*}{$<0.05^{*}$} \\
\hline & No & $191(52.5)$ & $21(37.5)$ & $170(55.2)$ & & \\
\hline \multirow{2}{*}{ Unhealthy eating } & Yes & $127(34.9)$ & $20(35.7)$ & $107(34.7)$ & \multirow{2}{*}{$1.05(0.58-1.89)$} & \multirow{2}{*}{ n.s. } \\
\hline & No & $237(65.1)$ & $36(64.3)$ & $201(65.3)$ & & \\
\hline \multirow{2}{*}{$\begin{array}{l}\text { Body } \\
\text { weight watching }\end{array}$} & Yes & $217(59.6)$ & $16(28.6)$ & $201(65.3)$ & \multirow{2}{*}{$0.21(0.11-0.40)$} & \multirow{2}{*}{$<0.001^{* \star *}$} \\
\hline & No & $147(40.4)$ & $40(71.4)$ & $107(34.7)$ & & \\
\hline \multirow{2}{*}{$\begin{array}{l}\text { Low physical } \\
\text { activity }\end{array}$} & Yes & $174(47.8)$ & 32 (57.1) & $142(46.1)$ & \multirow{2}{*}{$1.56(0.87-2.77)$} & \multirow{2}{*}{ n.s. } \\
\hline & No & $190(52.2)$ & $24(42.9)$ & $166(53.9)$ & & \\
\hline
\end{tabular}

$\mathrm{n}$ - number of subjects; SBP - systolic blood pressure; DBP - diastolic blood pressure; TCH - total cholesterol; LDL-CH - LDL-cholesterol; BMI - Body Mass Index; $\mathrm{Cl}$ - confidence interval; p-values $-{ }^{* * *}<0.001 ;{ }^{*}<0.05$; n.s. - not significant

\section{DISCUSSION}

Health care staff and medical doctors can serve as role models in the healthy lifestyle promotion. Health care staff are more likely to motivate change of unhealthy habits - such as unhealthy diets, physical inactivity, stress and smoking - among their patients and general public. With the rising prevalence of chronic diseases, such as cardiovascular diseases, obesity and diabetes, it is increasingly important for medical schools curricula to include subjects with learning opportunities in lifestyle management and behavioural counselling for future practitioners $(8,19)$.

Usually, medical and health science faculty students have better parameters of lifestyle than their colleagues from other universities. Extremely high academic demands and requirements during 6 years of study may affect the lifestyle habits and cardiovascular health determinants in negative way. Students need to spend many hours learning difficult basic fundamentals and clinical subjects. Stress factors, irregular and unhealthy eating, and higher prevalence of inactivity during studies can have negative consequences on their mental health status (7). On the other hand, high adaptability of the young organism and the short duration of exposure to risk factors means that the final effect is less significant than that of a chronic long term exposure to detrimental unhealthy lifestyle factors (11).

Only very small number of our participants (1.1\%) would be classified as hypertensive by WHO criteria (17). The prevalence of high blood pressure in adults in Slovakia (2008) is still high, approximately $42.7 \%$ of males and $37.2 \%$ of females $(11,18)$. Since 1993, the mean values of systolic blood pressure (SBP) dropped among Slovak men only by $2 \%$, for women by $7.2 \%$. Blood pressure is mostly higher in men than in women (10). The prevalence of untreated hypertension has significantly decreased since 1998 from $76 \%$ to $37 \%$ (11). Results of our survey have shown statistically significant differences $(p<0.05)$ in mean values of SBP and DBP between the two genders. BP over $120 / 80$ (which still cannot be accounted as a clinical pathology) was confirmed as SBP/DBP - in $10.99 \%$ versus $9.07 \%$ of our participants.

Over the past few decades, the world population transitioned from a state in which prevalence of underweight was more than double than that of obesity, to the one in which more people are overweight or obese, particularly in more developed countries in Europe and America (20). Although obesity rates in all European countries have increased significantly over the past three decades, based on the BMI measures in our study, only an extremely low number of medical students were obese with $\mathrm{BMI} \geq 30(0.8 \%)$. Declared prevalence of obesity in adult Slovakian population in 2008 was $25.4 \%$ of males and $25.4 \%$ of females (18). The prevalence of overweight in the study group of university students was therefore also significantly lower than that of average Slovak population. However, body fat percentage measures in our group 
Table 6. OR of cardiovascular risk factors for group of medical students with higher fat percentage $(N=364)$

\begin{tabular}{|c|c|c|c|c|c|c|}
\hline Parameter & Category & $\mathrm{n}(\%)$ & $\begin{array}{c}\text { Higher fat } \\
\mathrm{n}(\%)\end{array}$ & $\begin{array}{c}\text { Normal fat } \\
n(\%)\end{array}$ & OR $(95 \% \mathrm{Cl})$ & $\mathrm{p}$-value \\
\hline \multirow{2}{*}{ SBP } & Normal & $324(11.0)$ & $39(59.1)$ & $285(95.6)$ & \multirow{2}{*}{$15.18(7.23-31.86)$} & \multirow{2}{*}{$<0.001^{* * \star}$} \\
\hline & Higher & $40(89.0)$ & $27(40.9)$ & $13(4.4)$ & & \\
\hline \multirow{2}{*}{ DBP } & Normal & $331(90.9)$ & 48 (72.7) & $283(95.0)$ & \multirow{2}{*}{7.07 (3.34-14.98) } & \multirow{2}{*}{$<0.001^{* * *}$} \\
\hline & Higher & $33(9.1)$ & $18(27.3)$ & $15(5.0)$ & & \\
\hline \multirow{2}{*}{$\mathrm{TCH}$} & Normal & $256(71.9)$ & $26(39.4)$ & $230(77.2)$ & \multirow{2}{*}{$5.90(3.34-10.42)$} & \multirow{2}{*}{$<0.001^{* \star *}$} \\
\hline & Higher & $100(28.1)$ & $40(60.6)$ & $60(20.1)$ & & \\
\hline \multirow{2}{*}{ LDL-CH } & Normal & $297(83.4)$ & $28(9.4)$ & $269(90.6)$ & \multirow{2}{*}{$17.38(8.99-33.63)$} & \multirow{2}{*}{$<0.001^{* \star *}$} \\
\hline & Higher & $59(16.6)$ & $38(64.4)$ & $21(35.6)$ & & \\
\hline \multirow{2}{*}{$\begin{array}{l}\text { Perceived } \\
\text { health }\end{array}$} & $\begin{array}{l}\text { Excellent and very } \\
\text { good }\end{array}$ & $267(73.4)$ & $32(48.5)$ & $235(78.9)$ & \multirow{2}{*}{$3.96(2.27-6.92)$} & \multirow{2}{*}{$<0.001^{\star \star \star}$} \\
\hline & $\begin{array}{l}\text { Good, satisfactory } \\
\text { and poor }\end{array}$ & $97(26.6)$ & $34(51.5)$ & $63(21.1)$ & & \\
\hline \multirow{2}{*}{ Smoking } & Yes & $43(11.8)$ & $17(25.8)$ & $26(8.7)$ & \multirow{2}{*}{$3.63(1.83-7.18)$} & \multirow{2}{*}{$<0.001^{* * *}$} \\
\hline & No & $321(88.2)$ & 49 (74.2) & $272(91.3)$ & & \\
\hline \multirow{2}{*}{ Stress at university } & Yes & $173(47.5)$ & $35(53.0)$ & $138(46.3)$ & \multirow{2}{*}{$1.31(0.77-2.23)$} & \multirow{2}{*}{ n.s. } \\
\hline & No & $191(52.5)$ & $31(47.0)$ & $160(53.7)$ & & \\
\hline \multirow{2}{*}{ Unhealthy eating } & Yes & $127(34.9)$ & $26(39.4)$ & $101(33.9)$ & \multirow{2}{*}{$1.27(0.73-2.20)$} & \multirow{2}{*}{ n.s. } \\
\hline & No & 237 (65.1) & $40(60.6)$ & $197(66.1)$ & & \\
\hline \multirow{2}{*}{$\begin{array}{l}\text { Body } \\
\text { weight watching }\end{array}$} & Yes & $217(59.6)$ & $23(34.8)$ & $194(89.4)$ & \multirow{2}{*}{$0.29(0.16-0.50)$} & \multirow{2}{*}{$<0.001^{* * *}$} \\
\hline & No & $147(40.4)$ & $43(65.2)$ & $104(70.7)$ & & \\
\hline \multirow{2}{*}{$\begin{array}{l}\text { Low physical } \\
\text { activity }\end{array}$} & Yes & $174(47.8)$ & $40(60.6)$ & $134(45.0)$ & \multirow{2}{*}{$1.88(1.09-3.24)$} & \multirow{2}{*}{$<0.05^{*}$} \\
\hline & No & $190(52.2)$ & $26(39.4)$ & $164(55.0)$ & & \\
\hline
\end{tabular}

$\mathrm{n}$ - number of subjects; SBP - systolic blood pressure; DBP - diastolic blood pressure; TCH - total cholesterol; LDL-CH - LDL-cholesterol; BMI - Body Mass Index;

$\mathrm{Cl}$ - confidence interval; p-values $-{ }^{* * *}<0.001 ;{ }^{*}<0.05$; n.s. - not significant

indicate that participants had a higher prevalence of overweight than indicated by results of the BMI assessment. Neither of the used methods for adiposity assessment has proven to be superior in "discriminatory activities". As expected, BMI values and percentage body fat were significantly correlated to almost all cardiovascular risk variables; meaning that even students in the range of overweight and obesity were more likely to present a higher cardio-metabolic risk.

Mean TCH values in the entire study group are in concordance with the research of other authors (21) from the same faculty, who analysed the impact of the waist circumference on increased cardio-metabolic risk in healthy young medical students. Their paper confirmed the average TCH level for men $-4.4 \mathrm{mmol} / \mathrm{l}$; in our study it was $4.31 \mathrm{mmol} / \mathrm{l}$. For the group of females, the cholesterol levels in literature study (21) were $4.64 \mathrm{mmol} / \mathrm{l}$, while our research indicates an average of $4.52 \mathrm{mmol} / \mathrm{l}$. The same authors (21) have confirmed significantly higher TCH levels for females compared to males, which is in agreement with our outputs. In both studies, LDL-cholesterol analysis confirmed almost equal values while comparing males and females. In literature, LDL-CH arithmetic mean was $2.80 \mathrm{mmol} / 1$ for males vs $2.77 \mathrm{mmol} / 1$ for females (21) and our survey confirmed level of LDL-CH $2.67 \mathrm{mmol} / 1$ for males versus $2.85 \mathrm{mmol} / 1$ for females. When comparing the values of TCH and LDL-CH with the established standards, we can evaluate these standards as very strong $-28.0 \%$ of student confirmed higher TCH levels than $4.5 \mathrm{mmol} / 1$ and $16.57 \%$ of student surpassed the LDL-CH limit of more than $2.5 \mathrm{mmol} / \mathrm{l}$.

Our study results support the notion that medical students self-rate their health status highly, with very little occurrence of "poor health" grade. However, Brehm et al. study (10) for both males and females, reported a gradual increase in frequency of poor mental health (median of 3 days per month) throughout study at medical school, perhaps related to stressors such as academic demands, financial concerns, or life events (10). Our outputs find out that almost over 50 percent of participants experienced stress during their university studies, and there was no significant gender difference in the gender prevalence of university stress.

\section{Limitations of the Study}

Since all participants were examined only from one medical faculty, generalisation of results might be limited for similar institutions. Data also have been collected during period of 5 years (2010-2014), where could be also impact of the time trend difference. While the study assessed measurable anthropometric parameters (blood pressure, anthropometric examinations, and cholesterol level), we have used only a very brief questionnaires with limited data about behavioural and socioeconomic characteristic. Controversy remains over whether or not medi- 
cal school study process deteriorates the health status of their students. Therefore, a longitudinal design study should be used to confirm time trends in clinical, anthropological parameters and lifestyle factors during the university educations in the future. Also, a larger cohort of medical students from several universities $(21,22)$ would be needed to disseminate results as outputs from a representative national study.

\section{CONCLUSIONS}

This paper presents the results of a cross-sectional epidemiological survey performed amongst the general medicine students from the Faculty of Medicine, University of Pavol Jozef Šafárik in Košice. Sample included 364 students in their fourth year of studies. Our results indicate that medical students from the clinical, functional and biochemical point of view were generally healthy, with very small number of participants exhibiting values associated with clinical risk, particularly in parameters of $\mathrm{BP}, \mathrm{TCH}$, LDL-CH, BMI and body fat percentage. Therefore - and by using the general international criteria - the prevalence of obesity was (0.8\%), hypertension (1.1\%) and abnormal TCH profile $(8.7 \%)$. Prevalence of increased blood pressure (SBP/DBP 120/80 mmHg) among participants was $10.99 \%$ (SBP) and $9.07 \%$ (DBP). When evaluating overweight and obesity, we found $15.38 \%$ (BMI evaluation) versus $18.54 \%$ (body fat percentage evaluation) participants with increased risk for overweight + obesity. Statistical analysis confirmed higher prevalence of cardiovascular risk factors among males compared to females. Among the group of male students, the study has confirmed the following: higher SBP and DBP, higher BMI and body fat percentage, lower rate of self-perceived excellent and good health status, lower frequency of body weight watching and higher prevalence of unhealthy eating. The mean values of $\mathrm{TCH}$ and LDL-CH were statistically higher among females. Group of students classified as obese and overweight (evaluated by BMI and percentage of fat) were at significantly increased risk for development of higher SBP and DPB, higher TCH and LDL-cholesterol, perceived poorer general health and poorer body weight control. The results obtained in the survey imply higher cardiovascular risk in the sample of young males as well as in overweight and obese medical student's generation. However, the outputs of this survey demonstrate lower risk factors of cardiovascular diseases in young and adapted medical students, when compared to the Slovak general population. We have found that gender, overweight and obesity are predictors of cardiovascular risk factors even in the group of highly educated university students of medicine. It will be important to imply integration of behavioural, mental, habitual and social component of health promotion and prevention through the medical curricula with nutrition lectures, physical activity support, case studies, mental load prevention, online preventive modules and other forms of activities.

\section{Acknowledgements}

This work was supported by national grant KEGA 007UPJŠ-4/2018 - principal investigator Kvetoslava Rimárová and grant UPJŠ VVGS2018-897 - principal investigator Kvetoslava Rimárová.

\section{REFERENCES}

1. Alberty R, Studenčan M, Kovář F. Prevalence of conventional cardiovascular risk factors in patients with acute coronary syndromes in Slovakia. Cent Eur J Public Health. 2017 Mar;25(1):77-84.

2. The Health Statistics Yearbook of the Slovak Republic 2016. Bratislava: National Health Information Centre; 2014. (In Slovak.)

3. Đokić B, Đonović N, Tadić B, Nikolić D. Factors and estimation of risk for cardiovascular diseases among patients in primary health care in Central Serbia. Cent Eur J Public Health. 2015 Sep;23(3):195-9.

4. Frank E, Segura C, Shen H, Oberg E. Predictors of Canadian physicians' prevention counselling practices. Can J Public Health. 2010 Sep-Oct;101(5):390-5.

5. Frank E, Elon L, Spencer E. Personal and clinical tobacco-related practices and attitudes of U.S. medical students. Prev Med. 2009 Aug-Sep; 49(2-3):233-9.

6. Howe M, Leidel A, Krishnan SM, Weber A, Rubenfire M, Jackson EA. Patient-related diet and exercise counseling: do providers' own lifestyle habits matter? Prev Cardiol. 2010 Fall;13(4):180-5.

7. MacLean L, Booza J, Balon R. The impact of medical school on student mental health. Acad Psychiatry. 2016 Feb;40(1):89-91.

8. Lins L, Carvalho FM, Menezes MS, Porto-Silva L, Damasceno H. Healthrelated quality of life of students from a private medical school in Brazil. Int J Med Educ. 2015 Nov 8;6:149-54.

9. Frank E, Carrera JS, Elon L, Hertzberg VS. Basic demographics, health practices, and health status of U.S. medical students. Am J Prev Med. 2006 Dec;31(6):499-505.

10. Brehm BJ, Summer SS, Khoury JC, Filak AT, Lieberman MA, Heubi JE. Health status and lifestyle habits of US medical students: a longitudinal study. Ann Med Health Sci Res. 2016 Nov-Dec;6(6):341-7.

11. Avdičová M, Hrubá F. Genetic and exogenous risk factors of coronary artery disease in Slovak population - study results within CINDI Programe. Intern Med. 2002;2(8):467-72. (In Slovak.)

12. World Health Organization. Obesity: preventing and managing the global epidemic. Report of a WHO Consultation. WHO Technical Report Series; 894. Geneva: WHO; 2000.

13. Parizkova J. Total body fat and skinfold thickness in children. Metabolism. 1961 Oct;10:794-807.

14. Parizkova J. Body fat and physical fitness body: composition and lipid metabolism in different regimes of physical activity. Dordrecht: Springer; 1977.

15. Gemmill M, Hockley T. European cholesterol guidelines report. London: LSE Health \& Policy Analysis Centre; 2005.

16. European Association for Cardiovascular Prevention \& Rehabilitation, Reiner Z, Catapano AL, De Backer G, Graham I, Taskinen MR, et al. ESC/EAS Guidelines for the management of dyslipidaemias: the Task Force for the management of dyslipidaemias of the European Society of Cardiology (ESC) and the European Atherosclerosis Society (EAS). Eur Heart J. 2011 Jul;32(14):1769-818.

17. Whitworth JA; World Health Organization, International Society of Hypertension Writing Group. 2003 World health Organisation (WHO)/ International Society of Hypertension (ISH) statement o management of hypertension. J Hypertens. 2003 Nov;21(11):1983-92.

18. World Health Organization. Noncommunicable diseases country profile. Geneva: WHO; 2014.

19. Phillips E, Pojednic R, Polak R, Bush J, Trilk J. Including lifestyle medicine in undergraduate medical curricula. Med Educ Online. 2015 Feb 3;20:26150.

20. NCD Risk Factor Collaboration (NCD-RisC). Trends in adult body-mass index in 200 countries from 1975 to 2014: a pooled analysis of 1698 population-based measurement studies with 19.2 million participants. The Lancet. 2016 Apr 2;387(10026):1377-96.

21. Hertelyová Z, Vašková J, Vaško L. Waist circumference-to-height ratio detected in a convenient sample of young Slovak people with increased cardio-metabolic risk. Central Eur J Public Health. 2016 Jun;24(2):95-102.

22. Stephens MB, Cochran C, Hall JM, Olsen C. Physical fitness during medical school: A 4-year study at the Uniformed Services University. Fam Med. 2012 Nov-Dec;44(10):694-7.

\section{Conflict of Interests}

None declared 